\title{
RTU approach to sustainable development: governance and measuring impact
}

\author{
Juris Iljins ${ }^{1 *}$ and Leonids Ribickis ${ }^{2}$ \\ ${ }^{1}$ Juris Iljins*, Riga Technical University, Faculty of Engineering Economics and Management \\ ${ }^{2}$ Prof. Leonids Ribickis, Rector of Riga Technical University
}

\begin{abstract}
The aim of this article is to explore Riga Technical University (RTU) approach to Sustainable Development, sustainability governance practice and its impact. In order to successfully implement sustainability as an essential part of organizations daily operations, processes should be properly governed, communicated and adequate resources should be allocated. Implementation of sustainable thinking has helped RTU to re-evaluate processes, goals and outcomes. The concept of RTU in long-term is to move towards building holistic sustainability concept thus impacting social, economic and environmental issues. For the achievement of these goals, governance of sustainability is a crucial factor.
\end{abstract}

\section{Introduction}

In order to govern and implement sustainability concept, RTU has adopted two Strategic planning documents. One of these documents is RTU Strategy, where Sustainable development is seen as an important cornerstone, and it is integrated in main strategic objectives of university. Additionally, RTU Senate has adopted RTU Excellence approach to achieve organizational excellence and increase sustainability effort. The Approach defines process steps to set required results, plan approach, implement and assess outcomes. This approach defines RTU sustainability targets and priorities. RTU has set Sustainable Development Goals (SDG) where university tends to make an impact. RTU as its priorities has defined seven SDG. Within these actives RTU has prioritized its actions to make impact not only by contribution to research, projects and activities, but also by implementing these goals in the work culture of RTU. Impact of each SDG is measured. Additionally, in order to facilitate green thinking and reduce environmental impact, RTU has adopted its Green Policy, that focuses on three core criteria: Green Energy, Eco thinking and Sustainability - Competiveness.

\section{RTU approach to sustainable development}

RTU acts to promote sustainable development of Latvia, it facilitates achieving the goals of the European Higher Education Area, society, employers, students, alumni, and other stakeholders. The University has integrated the concept of sustainable development within its Strategy, value chain, and processes; it provides the necessary resources to achieve these goals. Sustainable development is inextricably connected with concerns about sustaining the environment and mitigation of negative environmental impacts. Within the framework of RTU Environmental Policy, measurements are taken to optimize the consequences of activities, product life cycle and services, and to mitigate their impact on public health, security and environment.

Introducing its approach to pursuing excellence, Riga Technical University has defined the stages of the process leading to excellence. The stages of RTU Excellence Approach (Fig. 1) reflect organizational culture of RTU and serve as a common language that ensures common understanding of the University quality issues, which, in its turn, promotes sustainable development and achievement of the University goals.

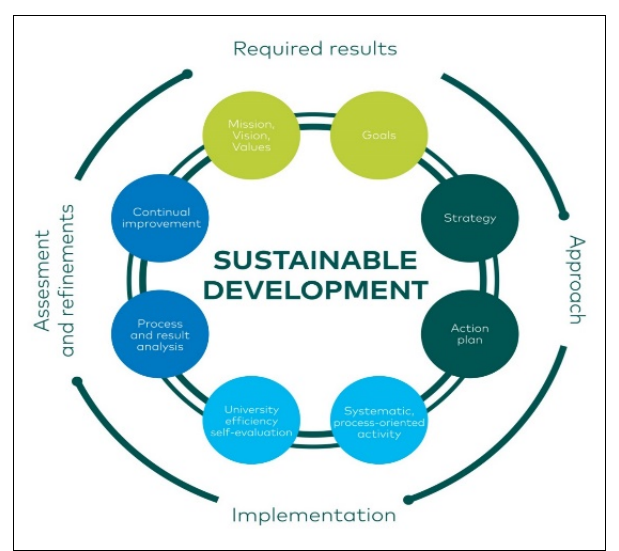

Fig. 1. Stages of RTU approach to pursuing excellence. Source: RTU approach to pursuing excellence (2017) [2].

Fig. 1 presents the process cycle of ensuring excellence. Initially, RTU Mission, Vision and Values are set by RTU Senate and administration. They are mainly focused on setting achievable goals, developing and

\footnotetext{
${ }^{*}$ Corresponding author: juris.iljins@rtu.lv
} 
reinforcing more competitive national economy through creation of additional value for perspective graduates and existing students. Keeping this in mind, RTU has set its goals that are implemented within RTU Strategy, which focuses on high quality study process, excellence in research and sustainable valorization [1]. Once all strategic objectives are set, action plan is drawn up by listing concrete activities on how to improve university performance and to help achieve the targets set previously. Implementation phase begins with systematic process-oriented review of the real time data. Analysed data is used to further enhance the process or make conclusions on the set targets. This is conducted by RTU Quality Management Unit. Once a year, the university prepares a self-evaluation report to analyse the processes and consider possible improvements in the future in terms of Action Plan and Strategy implementation process. After self-evaluation and analysis of performance data, proposals for administration to introduce further changes for continuous improvement are made [4]. Sustainability is core component in different strategic documents of RTU. For example: RTU Constitution, Strategy, Quality Policy and external quality concepts or standards like EFQM excellence model, UN SDG and European Standards and Guidelines.

\subsection{Priority SDG}

RTU Deans Council has defined the most important UN SDG goals that university focuses attention on. Within these sustainable development goals RTU plans strategic development objectives [3].

Goal 4. Ensure inclusive and equitable quality education and promote lifelong learning opportunities for all.

One of the main objectives of RTU Strategy is to plan and ensure high quality study process, provide students and other stakeholders with knowledge, which will help them meet future goals and promote their talent. RTU offers life-long learning opportunities to everyone. Ensuring high quality education, RTU provides opportunities to students from all over the world.

Goal 6. Ensure availability and sustainable management of water and sanitation for all.

Scientific activities of Riga Technical University and research on water treatment provide the basis for sustainable development. RTU researchers are developing new water treatment equipment, which will purify water and make it more accessible in various conditions. Water treatment equipment developed at RTU will be available to individual consumers.

Goal 7. Ensure access to affordable, reliable, sustainable and modern energy for all.

Ii is difficult to imagine contemporary life and business without electricity, heat energy and fuel, in other words, without power supply. Economic development, world population growth and urbanization impose ever growing requirements on power supply systems. Recognizing that the volume of non-renewable energy sources is gradually decreasing (oil, coal, natural gas, etc.), sustainable electric power supply has become one of the main challenges. RTU researchers working within the research platform "Energy and Environment" develop technologies and solutions for cheap and accessible energy.

Goal 9. Build a sustainable infrastructure, promote inclusive and sustainable industrialization and foster innovation.

Infrastructure and industrialization are a research priority of Riga Technical University. The scope of research conducted at the University in the field materials is very wide, ranging from nanoparticle synthesis to large, practically applicable construction calculations, structural strength testing and long-term forecasting.

Goal 11. Make cities and populated areas inclusive, safe, resilient and sustainable.

Contemporary cities are a vivid proof of developments in science and technology, that is why urbanization issues are topical on the global scale, and researchers all around the world address these issues. Most of the world resources are consumed in cities, where the largest part of world population resides. Cities as the drives of economic development, culture and innovation centres attract people to live, study and work there. At the same time, concentration of population poses challenges for specialists in urban development. Sustaining of cultural and historical heritage, dwelling, mobility and infrastructure provision, employment and social issues this wide range of issues illustrates a complex cross disciplinary character of urban development.

Goal 12. Ensure sustainable consumption and production patterns.

Research in the field of security and defence is inextricably connected with the state interests; therefore, active collaboration with state governance structures is vital. RTU research platform "Security and Defence" has been established to promote cross-disciplinary research in the fields connected with individual and state security. Research areas in the field of defence cover a wide range of problems, as contemporary world threats are complex. Their elimination is a great challenge for researchers and various industries.

Goal 17. Revitalize the global partnership for sustainable development.

In order to reach the above-mentioned goals, Riga Technical University is actively looking for cooperation partners in Latvia and abroad. RTU partner institutions can be found on all continents and are united by common interests and sustainable solutions. 


\subsection{Governance}

RTU as Quality Model system has European Foundation for Quality Management excellence model. Principles defined in the EFQM Excellence Model and various higher education and quality standards are horizontally integrated with the stages of RTU Excellence Approach. These principles characterize the approach to pursuing excellence and sustainable development that RTU has adopted Fig. 2.

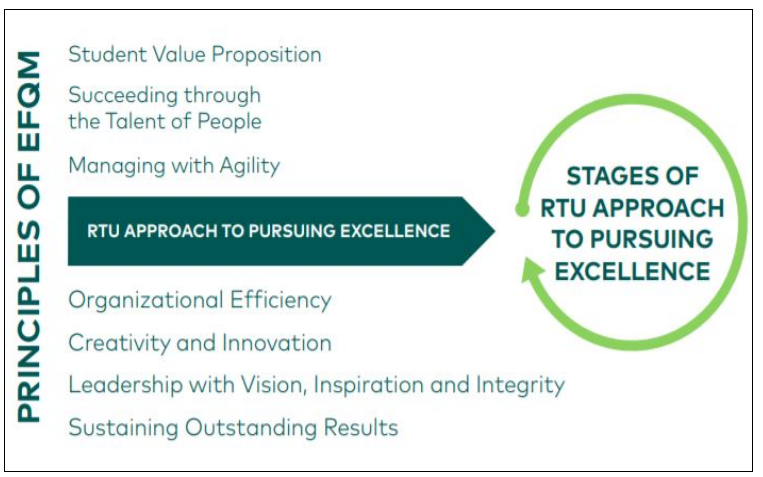

Fig. 2. Integration of the principles of EFQM excellence model in RTU approach to pursuing excellence

Source: RTU approach to pursuing excellence (2017) [2].

The structure of RTU Excellence Approach provides the basis for maintaining high level of University performance, a prerequisite for continual development of RTU to achieve sustainable performance results and excellence.

RTU has adopted its Green Policy which focuses on three main corner stones with sub-targets:

1. Climate and Green Energy

a. Energy resource optimization

b. Building energy efficiency

2. Eco - Thinking
a. Recycling
b. Toxic waste utilization
c. Social contribution in environmental clean-up and thinking

3. Sustainability and Competiveness
a. Green Thinking in all areas of University operation
b. Green Campus concept
c. Participation in international sustainability networks

Within GreenMetrics Rankings RTU has managed to achieve the best indication in area of Energy and Climate Change.

\subsection{Measuring impact}

To achieve the sustainable development KPI that are set in RTU Strategy, different environmental protection processes are adopted at RTU. Achievable targets are monitored, and corresponding policy impact is evaluated each year. The most important issue is to reduce universities environmental impact in energy consumption rate. RTU as a public entity has some limitations in this aspect.

In waste management RTU is monitoring waste output and recycling targets. In transportation RTU is moving towards using only electrical vehicles and bicycles within RTU campus. In table 1 and table 2 some targets with impact can be seen.

Table 1. Energy consumption targets at RTU, year 2016 - 2018

\begin{tabular}{|l|l|l|l|}
\hline Resource & $\begin{array}{l}\text { Target } \\
\text { in 2016 } \\
\text { against } \\
\text { (year } \\
\mathbf{2 0 1 5 ) , \%}\end{array}$ & $\begin{array}{l}\text { Target in } \\
\mathbf{2 0 1 7} \text { against } \\
\text { (year 2015), } \\
\text { \% }\end{array}$ & $\begin{array}{l}\text { Target in } \\
\mathbf{2 0 1 8} \\
\text { against } \\
\text { (year } \\
\mathbf{2 0 1 5 ) , ~ \% ~}\end{array}$ \\
\hline Power & $+5 \%$ & $+2 \%$ & $-1 \%$ \\
\hline $\begin{array}{l}\text { Heat } \\
\text { Energy }\end{array}$ & $+15 \%$ & $+10 \%$ & $+5 \%$ \\
\hline Water & $-3 \%$ & $-7 \%$ & $-11 \%$ \\
\hline
\end{tabular}

As it can be seen all energy consumption rates are planned against benchmarking year. Next benchmarking year will be 2018 and future targets will be planned against the indicator.

Table 2. Transport efficiency targets at RTU, year 2016- 2018

\begin{tabular}{|l|l|l|l|}
\hline Activity & $\begin{array}{l}\text { Target } \\
\text { in year } \\
\text { 2016 }\end{array}$ & $\begin{array}{l}\text { Target in } \\
\text { year 2017 }\end{array}$ & $\begin{array}{l}\text { Target } \\
\text { in year } \\
\mathbf{2 0 1 8}\end{array}$ \\
\hline $\begin{array}{l}\text { Usage of } \\
\text { electric cars } \\
\text { at campus }\end{array}$ & $\begin{array}{l}80000 \\
\mathrm{~km}\end{array}$ & $90000 \mathrm{~km}$ & $\begin{array}{l}100000 \\
\mathrm{~km}\end{array}$ \\
\hline $\begin{array}{l}\text { Bicycle } \\
\text { parking } \\
\text { spaces }\end{array}$ & $\begin{array}{l}60 \% \\
\text { building } \\
\mathrm{s} \\
\text { accessibl } \\
\text { e }\end{array}$ & $\begin{array}{l}70 \% \\
\text { buildings } \\
\text { accessible }\end{array}$ & $\begin{array}{l}80 \% \\
\text { building } \\
\text { s } \\
\text { accessibl } \\
\text { e }\end{array}$ \\
\hline
\end{tabular}

Targets in table 1 and table 2 are fallowed by action plan on how to achieve these targets. Additionally, there are key targets that are not included in this article for waste management and green thinking information campaigns. In similar fashion each SDG targets subtargets planned indicators are prepared and measured.

\section{Conclusion}

Recent development of RTU has been mainly achieved due to the adopted RTU Development Strategy 2014 2020 and introduction of the European Foundation for Quality Management (EFQM) management model. RTU Strategy focuses on three pillars - high quality study process, research excellence and sustainable innovation and commercialization. RTU has introduced the EFQM management system as the basis for operations to support implementation of the strategy and to ensure process efficiency and quality. The proposed model and actions to introduce sustainable integrated concept are based on the Planning Stage, Approach, Implementation, Assessment and Refinement. The method on how to define action plan priorities has been adopted to suit the 
needs of RTU. Further RTU plans to develop its Green Campus concept to create university community that focuses on sustainability. This includes not only mentioned green thinking concept, driving electro vehicles and bicycles, green projects, but also to develop green entrepreneurial thinking. This will include new green technology innovation, support for green technology start-up businesses and environmentally friendly solutions within university itself for daily operations.

\section{References}

1. Riga Technical University, Strategy of Riga Technical University 2014-2020, Approved by the Decision of the Senate of RTU, (2013)
2. Riga Technical University, RTU Excellence approach, Approved by the Decision of the Senate of RTU, (2017)

3. Riga Technical University, Available online at https://www.rtu.lv/en/university/strategy/sustainable -development/rtu-goals

4. Iljins, J., Zeps, A., Ribickis, L., RTU Approach to Pursuing Excellence: Sustainable Integration of Internal Quality System in the Strategy Development. Pilot Project Review, Proceedings of the 45th SEFI Annual Conference, Portugal, Angra do Heroismo, pp.661-668. ISBN 978-989-98875-72. (2017). 